Journal of Systems Science and Information

Dec., 2016, Vol. 4, No. 6, pp. 489-504

DOI: $10.21078 /$ JSSI-2016-489-16

\title{
Review on Financial Innovations in Big Data Era
}

\author{
Xiong XIONG \\ Department of Management and Economics, Tianjin University, Tianjin 300072, China; Key \\ Laboratory of Computation and Analytics of Complex Management Systems (CACMS), Tianjin \\ 300072, China \\ Jin ZHANG \\ Department of Management and Economics, Tianjin University, Tianjin 300072, China \\ Xi JIN* \\ School of Economics, Tianjin University of Finance and Economics, Tianjin 300222, China \\ E-mail: congoz@sina.com
}

Xu FENG

Department of Management and Economics, Tianjin University, Tianjin 300072, China; Key

Laboratory of Computation and Analytics of Complex Management Systems (CACMS), Tianjin

300072, China

\begin{abstract}
The rise of Big Data brings the financial innovation opportunities as well as challenges. This paper reviews different fields of big-data-based financial innovations as well as the scientific discoveries and theoretical breakthroughs of risk analysis with respect to these financial innovations. Based on the current research status, several key problems are put forward and their relative solutions are discussed. The three mean aspects are listed as the pricing and risk measuring for data-driven financial innovation products or services; the changes that data-driven financial innovation would bring to finance industry, which involve operation, resources allocation and ecosystem; and questions and solutions of systemic risk management based on Big Data analytics. Finally, predictions towards the hotspots frontier and developing trends for further data-driven financial innovation are proposed.
\end{abstract}

Keywords big data; financial innovation; online information; trends

\section{Introduction}

With the advantage of Big Data era, data has become another crucial driving force for financial market to innovate following the existing elements: Cost, regulation and technique. The Interment and social media are now available to record the spread of information, online trading data, personal identity and behaviours, which can hardly be obtained before. Inherent logic and cross-correlation could be inferred among different dimensions of data through analysis

Received January 19, 2016, accepted March 24, 2016

${ }^{*}$ Corresponding author

Supported by National Natural Science Foundation of China (71320107003, 71532009, 71201112), Core Projects

in Tianjin Education Bureaus Social Science Program (2014ZD13) 
and integration of "massive multidimensional data", which inconvenient for financial institutions to realize and understand the personal characteristics and behaviors of the participants in financial market, thus booming a series of financial products and services innovation.

Along with a lot of opportunities, big data driving force also brings the finance industry some difficulties and challenges. Big Data Prospect Report from McKinsey Global Institute see real innovative potential in finance industry among all, but also notices its difficulties to form a data driven innovation ideas, due to the research of pricing and risk management of "datadriven" financial innovations is still in its preliminary stage, and the relevant theories need to be further refined and justified. At present, the research of financial innovation, asset pricing and risk management based on financial big data is just unfolding, and now look at the overall situation of financial system instead of merely the stock market in previous studies. It is far from being a unified framework, despite some important scientific discoveries and theoretical breakthroughs. Edelman ${ }^{[1]}$ and Varian ${ }^{[2]}$ published Using Internet data for economic research and Big Data: New tricks for econometrics in Journal of Economic Perspectives, establishing the formation of research paradigm in this field. Certain important scientific discoveries and theoretical breakthroughs are found about financial innovation and risk analysis theory based on big data, and can be divided into three directions - financial innovation of online P2P lending, the behavior evolution of securities market participants, systemic risk in the network perspective and its impact to financial institutions.

This paper first reviews important scientific discoveries and theoretical breakthroughs of financial innovation and risk analysis theory based on Big Data in above three directions, then extracts key problems worth exploring at the production, industry and system level based on the research status and development trends at domestic and abroad; meanwhile, discusses the methodology and significance of solving the problems above. Finally, taking important achievement and practical into account to predict possible hotspots frontier and developing trends of this field in the future.

\section{Study on the Financial Innovations of Online P2P Lending Platform}

Online P2P lending platform is an important financial innovation driven by big data, which replaces the traditional form of lending channel from banks and other financial institutions and bridges the demand-side and the supply-side of money through information technology. Since it emerged, this financial innovation has drawn continuous attention of academia. According to the research perspective, the relevant achievements can be divided into four categories as follows:

\subsection{Study on the Decision Preference of Investors of Online P2P Lending Platform}

Previous studies about online P2P lending platform were meanly focus on the decisionmaking strategies of investors. Paravisini, et al. ${ }^{[3]}$ estimated investors' risk preference by studying their portfolio choices in online P2P lending platform; Zhang ${ }^{[4]}$ studied from perspectives of informational social impact and herding behavior to explain how individual investors' participation of online financial community influenced their credit risk preference in online $\mathrm{P} 2 \mathrm{P}$ lending marketplaces under different financial situations. The research concluded that online financial participants preferred to higher risk than non-participants in period without the threat 
of financial crisis, while, they were more risk averse than non-participants during financial crisis period. Li, et al. ${ }^{[5]}$ studied the heterogeneous decision-making behavior of borrowers in online P2P lending platform. Krumme, et al. ${ }^{[6]}$ studied the dynamic behaviors of online P2P lending. Yum, et al. ${ }^{[7]}$ examined how individual investors form their decisions among the group information in the online P2P lending. Ceyhan, et al. ${ }^{[8]}$ studied the dynamics of bidding behavior in the online P2P loan auction. They observed herding behavior and then built a model to explain this phenomenon. Krumme, et al. ${ }^{[6]}$ and Li, et al. ${ }^{[9]}$ studied the group behaviors of online P2P lending markets participants with the effects of social interactions and multidimensional friendship networks. Herzenstein, et al. ${ }^{[10]}$ studied herding behavior in P2P loan auctions. Their paper indicated every $1 \%$ increase in the number of bids would boost the likelihood of follow-up bid by $15 \%$, unless the target amount has been achieved, herding diminished (a $1 \%$ increase in bids increases the likelihood of an additional bid by only $5 \%$ ). They also found a positive association between herding in the loan auction and its subsequent performance concluded that herding strategy in P2P loan auctions benefits bidders. Lee and Lee ${ }^{[1]}$, Luo and $\operatorname{Lin}^{[12]}$ discovered similar fact. The largest online P2P lending platform in South Korea is Popfunding.com, which enables lenders to vote on the trustworthiness of borrowers who make loan requests. Yum, et al. ${ }^{[7]}$ explored how the collective wisdom works for lending decisions by studied the case of Popfunding.com. They showed that the voting mechanism in Popfunding.com is a more efficient information conduit to improve efficiency when the information censorship was defective. However, facing sufficient verifiable information, lenders turned to rely on their own reasoning and ignore the collective opinion of the market. Li, et al. ${ }^{[13]}$ studied the factors that affect project success rate of borrowing in Chinese P2P micro credit lending.

\subsection{Study on Determination of the Interest Rate of the Online P2P Lending Plat Form}

Since Peer-to-peer (P2P) lending is an innovative financial intermediary, it does matter to determine its interest rates. Chen et al. ${ }^{[14]}$ applied the mathematical modeling approach to find that neither the complete information environment nor the incomplete information environment, the auction model proposed by Prosper can offer borrowers the lowest interest rate. For Prosper, who charges fees according to the volume of lending, this transaction method brings the largest volume of lending. In the study of the whole transaction recognition, Redmond, et al. ${ }^{[15]}$ tried to using the data of Prosper's customers who made transactions of both borrowing and lending to distinguish whether their behavior indicated arbitrage or money-laundry. Based on individual cash flows network model, they showed that there existed some customers who try to arbitrage by the spread, however, their behaviors did not always indicate significantly positive profits due to the possibility of defaults. Burtch, et al. ${ }^{[16]}$ carried out similar research. They established capital flows of loans among nations by collecting data from Kiva.org, and their findings suggested that the cultural differences and regional differences would affect the chance of successful lending. However, when taking the collateral regime of the third party into account, the influences of these differences on successful borrowing and lending would decline. Lin, et al. ${ }^{[17]}$ analyzed the data between 2007 and 2008 of the Prosper with social network function to study the effects of the circle of friends in the online P2P lending market with asymmetric information. Their findings indicated that, usually, borrowers with creditworthy friends 
were more likely to raise money, and with a lower interest rate. When tracing back this phenomenon's reason, they found that these kinds of borrowers had lower default rate. Researches about how borrowers' characteristics would influence their borrowing behavior also focusing on their credit grade, debt-to-income ratio, FICO score, revolving line utilization (see Emekter, et al. ${ }^{[18]}$ ), unaudited personal financial disclosure (see Michels ${ }^{[19]}$ ), gender (see Barasinska and Schafer ${ }^{[20]}$ ), appearance (see Ravina ${ }^{[21]}$ ) and the description of the borrowing reasons (see Larrimore, et al. ${ }^{[22]}$ and Herzenstein, et al. ${ }^{[23]}$ ). In general, in the online P2P lending market with asymmetric information, both the borrowers' individual financial properties (credit grade, previous borrowing behaviors, financial situation etc). And unquantifiable functions such as the description of the borrowing reasons and other properties of the borrowers would affect the successful rate of loan and interest rate.

\subsection{Study on Product Pricing and Return of the Online P2P Lending Platform}

Based on the analysis of the online P2P lending behavior, scholars had done further studies on the aspects of the product pricing and the return. For instance, Lin, et al. ${ }^{[17]}$ studied the friendship in the online P2P lending pattern. Herzenstein, et al. ${ }^{[23]}$ investigated the unverified information's influence on long-term debts' performance. Luo and Lin ${ }^{[12]}$ applied decision tree model to study the herding behavior in the online P2P lending, their findings showed that the investors' gains would significantly decline due to the herding behavior. Michels ${ }^{[19]}$ used the online P2P lending data to investigate the unverifiable disclosures' effects on the behavior of borrowing and lending, the results showed that the additional unverifiable disclosure was associated with a $1.27 \%$ reduction in interest rate and an $8 \%$ increase in bidding activity. Ashta and Assadi ${ }^{[24]}$ did the research on the perspective of social networking tools to detect whether efficient information dissemination could lower the trading cost. Meanwhile, some scholars shed more light on the auction in online $\mathrm{P} 2 \mathrm{P}$ lending communities from the perspective of traditional economic theories. For example, the research on the bidding process of online auctions in $\mathrm{P} 2 \mathrm{P}$ lending communities (see Herzenstein, et al. ${ }^{[25]}$ ), and the research on the bilateral market pricing strategy in online P2P lending market (see Qiu, et al. ${ }^{[26]}$ ).

\subsection{Study on Credit Risk of the Online P2P Lending Platform}

Although there are numerous advantages of online P2Plending mode, its risks are also obvious, including financial fraud, identity theft, and money-laundry, which would also appear in the traditional lending and these risks would be boosted by the Internet. Berger and Gleisner ${ }^{[27]}$ studied on the data based on more than 14000 loans and found that online financial intermediation significantly improved the credit conditions of the borrowers. Iyer, et al. ${ }^{[28]}$, Iyer, et al. ${ }^{[29]}$ investigated how the lenders judge the credit grade of the borrowers in online P2P loans. Wang and $\operatorname{Lin}^{[30]}$ did research on the dynamic credit risk management of online P2P loans, and they pointed out that ordinary personal credit rating method such as FICO score cannot adapt to the dynamic credit risk management elastically. Emekter, et al. ${ }^{[18]}$ also investigated the individual credit risk in online P2P lending. Moreover, Freedman and $\mathrm{Jin}^{[31]}$ studied the asymmetric information in online P2P loans, they discussed in this pattern, how the social network decrease the risks brought by the asymmetric information; $\operatorname{Lin}^{[32]}$ took this aspect into consideration as well. Weiss, et al. ${ }^{[33]}$ did empirical research on how online P2P lending mode reduces the 
risk of adverse selection from the aspects of market level. Puro, et al. ${ }^{[34]}$ and Zhao, et al. ${ }^{[35]}$ investigated how to recommend appropriate products to the customers in online P2P lending market from the perspective of individual portfolio risk management, including suggestions on initial interest rate and loan amount. Luo, et al. ${ }^{[36]}$ built a model to help investors to evaluate the potential benefits and risks of investment correctly in online P2P lending, thus helping them with the optimal investment decision. Riggins and Weber ${ }^{[37]}$ considered the recognition bias in the online P2P lending and proposed an analytic model.

Existing research of online P2P platform mainly focused on single platform. The research on: Cross-platform credit risk analysis and industry risk contagion; profound analysis for the financial fraud, bankruptcy in China P2P industry; relationship between the market participants' online information searching behavior and the financing capacity of the P2P platform, requires further research focus.

\section{Study on Behavior Evolution in Social Media of Stock Market Par- ticipants}

In the era of big data, information creation, interaction and transformation becomes different in social media as before. All kinds of information obtained from social media provided possibility to research for relationship between information and investor behaviors. This section classified the existing research into three catalogs according to behavior evolution in social media of stock market participants.

\subsection{Study on Information Release Behavior of Participant in Social Media}

When it comes to the behavior of releasing information in the social media, the academia has two distinct points of view: Noise and information. The debates can be dated back to Batsell ${ }^{[38]}$, Bennett $^{[39]}$, Goldstein ${ }^{[40]}$, Harmon ${ }^{[41]}$, Maremount ${ }^{[42]}$ and Medill ${ }^{[43]}$ over "implicating content between investing facts and fiction which comes from electronic message boards" in Seattle Times, Dow Jones News Service, Dallas Morning News, New York Times, Wall Street Journal and Chicago Daily Herald.

Wysocki $^{[44]}$ started academic study in this field, using a sample of over 3,000 stocks listed on Yahoo! electronic message boards, the study analyzed relationship between the number of posts and changes of stock price movement. The study showed that cumulative posting volume is highest for firms with extreme past returns and accounting performance on average, high market capitalization, high price-earnings and market-to-book ratios, high volatility and trading volume, high analyst following and low institutional holdings. And overnight message-posting volume was founded to predict changes in the next day stock trading volume and returns; indirectly proving posting behavior on electronic message boards was related to underlying firm characteristics, not noise. The tricky thing is, Tumarkin and Whitelaw ${ }^{[45]}$ captured nearly 200,000 messages from Raging Bull during April 1999 to February 2000 and found a statistically insignificant relationship between posting behaviors on electronic message boards and excess returns, which also proved from another side that market was efficient, and contents on electronic message boards were noise. Afterwards, the conclusion of researches did by Browen, et al. ${ }^{[46]}$, Clarkson, et al. ${ }^{[47]}$ and Dewally ${ }^{[48]}$ on electronic message boards also supported implicating 
contents as finance information. With the development of social media, economists gradually focused on information content in social media other than electronic message boards, such as spam(Bohme and Holz ${ }^{[49]}$, Hanke and Hauser $\left.{ }^{[50]}\right)$, blog $\left(\mathrm{Hu}\right.$, et al. ${ }^{[51]}$ and Saxton $\left.{ }^{[52]}\right)$, searching engine (Mondria, et al. ${ }^{[53]}$, Zhang, et al. ${ }^{[54]}$ ). For instance, Hank and Hauser regarded unsolicited e-mails as spam. They investigated the effects of stock spam e-mails on excess returns, turnover, and intra-day price range. The research proved that private information in spam could influence stock price; $\mathrm{Hu}$, et al. ${ }^{[51]}$ investigated the relationship of the blog visibility of SP 500 firms in Blog pulse and its capital market valuation. They found a positive association between a firm's blog visibility and its capital market valuation. Moreover, the visibility of firm's blog would influence its stock trading. Zhang, et al. ${ }^{[54]}$ obtained information content indicator of individual stocks in Baidu search engine with search-engine-based data mining algorithm, and found that this indicator could explain abnormal returns in stock. The empirical test proved that information content in search engines was not noise.

\subsection{Study on Building Proxy Based on Information Content from Participant}

This section of study regards content of information released in the social media from stock market participant as the premise, further research on text content classification, key words extraction, indicators of the whole market based on data mining algorithm and nature language processing tools had been done to study the relationship between these indicators and asset pricing.

Antweiler and Frank ${ }^{[55]}$ obtained data that contained 1.5 million messages of 45 listed companies, which were ranked in the Dow Jones Internet index (Dow Jones Internet Index) and the Dow Jones industrial average (the Dow Jones Industrial Average) on Yahoo! Finance and Raging Bull. They built a Bullishness indicator by using the Naive Bayes text Classification methods, and found that this indicator could predict the volatility of market, which was "statistically significant but small economically correlated (statistically significant but economically small)" between the indicator and returns. Das and Chen ${ }^{[56]}$ got posts on Yahoo! Finance message boards of 24 high-tech companies which were ranked in the Morgan Stanley High-Tech Index (MSH), using voting scheme method to extract indicator of investor sentiment, and discovered the significant correlation between the indicator and trading volume as well as stock volatility. Zhang, et al. ${ }^{[57]}$ used a variety of text classifier models to build the Sentiment Indexes of individual investors from posts on message board of Thelion! Wall Street Pit, and proved this sentiment index to be a significant directional indicator of "same-day positive but next-day negative".

Meanwhile, Bollen, et al. ${ }^{[58]}$ extracted the indicator characterizing public sentiment from Twitter by using software Opinion Finder and GPOMS, which considered to be significantly improving the prediction direction of Dow Jones industrial average (DJIA). Similar studies of constructing such indicator based on text content in social media also carried out by Felton and Kim ${ }^{[59]}$, Gu, et al. ${ }^{[60]}$, De Choudhury, et al. ${ }^{[61]}$ etc.

\subsection{Study on Financial Theory of Structuring Proxy Variables Based on Big Data}

Based on the research mentioned before, scholars are not satisfied with discovering interesting phenomenon from information extracted from the social media, but rather prefer to 
construct new proxy variables to verify existing finance theories or reasonable scientific hypothesis.

Da, et al. ${ }^{[62]}$ creatively applied search volume index of stock codes from Google Trends as the proxy variables of investor attention $\left(\mathrm{Merton}^{[63]}\right.$; Sims ${ }^{[64]}$; Hirshleifer and $\mathrm{Teoh}^{[65]}$; Grullon, et al. ${ }^{[66]}$; Chemmanur and Yan ${ }^{[67]}$; Chan ${ }^{[68]}$; Fang and Peress ${ }^{[69]}$; Barber and Odean ${ }^{[70]}$; Seasholes and $\left.\mathrm{Wu}^{[71]}\right)$. Plenty of studies showed the increasing of investor attention could forecast the rise of stock price two weeks later, and the prices would reverse within a year, which could explain the phenomenon of first day premium and long-run underperformance in IPOs. Bank, et al. ${ }^{[72]}$ also adopted daily data of search volume index from Google Insights to build proxy variables of investor attention. Their study indicated the increasing of investor attention would bring short-term positive return and promote market liquidity, and the enhancement of market liquidity was attributed to the reduction of market information asymmetry by investors' searching behavior. Vlastakis and Markellos ${ }^{[73]}$ adopted Google Trends search volume index as proxy variable of information demands. Their study showed that in consideration of market return and information supply, a positive relationship between information demands and historical and implied volatility was caught, and a higher demand of information was required under the high return. Drake, et al. ${ }^{[74]}$ also used Google Trends search volume index as a proxy for investor information needs, and found that the information demand from investors began to increase two weeks before the publish of earnings announcement, peaking at the exact day of announcement publishing, and could last a period of time. Thus proved market information is non-instant transmission, which verified the positive relationship between information demand and media attention. Dzielinski ${ }^{[75]}$ applied Google Trends search volume index as a proxy variable of economic uncertainty, and found economic uncertainty usually associated with stock market overall yield and volatility. Yu and Zhang ${ }^{[76]}$, Zhang, et al. ${ }^{[77]}$ studied the relationship between Chinese investor attention and stock market by introducing Baidu Index, which similarly discovered that investor attention would cause abnormal stock returns. Liu, et al. ${ }^{[78]}$ applied Baidu Index as proxy variable of media attention and investor attention, and found the changes of investor attention due to media information dissemination were the direct cause of abnormal stock returns. In addition, Zhang, et al. ${ }^{[79]}$ defined Baidu News as proxy variable of Internet information arrival (Lamoureux and Lastrapes ${ }^{[80]}$, Kalev, et al. ${ }^{[81]}$, Wagner and Marsh $^{[82]}$, Fleming, et al. ${ }^{[83]}$ and McMillan and Garcia ${ }^{[84]}$, combining with SMEs board Index to study Mixture Distribution Hypothesis. This empirical study indicated Internet information arrival could better explain volatility persistence in stock market compared to other variables.

At present, researches on the behavior evolution of stock market participants in social media mainly focused on the relationship between the capital market and information contained in a single social media. The impact of cross-correlation of multiple data sources on stock market and behavior evolution of other market participants in the financial system (e.g., Banking and Insurance) still required further studies.

\section{Systemic Risk and Financial Institutions: A Network Perspective}

Banking industry is a critical part of the financial market, which directly linked to safety of the financial system. After the financial crisis of 2008, the academic research turned to focus on 
the risk contagion in the banking system, which is the improper solution to a single bank crisis may lead to the falling of the whole banking system and the whole financial market. Existing researches on risk contagion and systemic risk study mainly focused on the following field:

\subsection{Theoretical Studies Based on Social Media of Information Diffusion Network in Financial Market}

This kind of research mainly focuses on the equilibrium between fraud information sender and receiver, and how does this equilibrium affect asset pricing. The cheap-talk model proposed by Crawford and Sobel ${ }^{[85]}$ is the most widely used framework. In this framework, it is assumed that the sender has private information that could affect the firm's future cash flows; however, they choose different releasing strategies (release true or false information) to affect their receivers in order to maximize their own profit. On the other hand, the receivers will learn from the sender's past behavior and try to distinguish whether the information is true or false, in order to make best use of secondhand information to maximize their profit. Existing literature mainly focused on single information source and multi information source. The multi-information sources research is based on the characteristics of information diffusion network due to multi information source in social media, to theoretically explain the influence of information source fraud behavior on asset pricing.

On the single information source perspective, Benabou and Laroque ${ }^{[86]}$ applied this framework to the information diffusion process in the stock market, presenting the equilibrium of single sender and receiver in the market to analyze the welfare loss in the condition of information manipulation. This result provided good explanation to certain kinds of information manipulation behavior in the market. Several scholars extended their study with individual behavior: Crawford ${ }^{[87]}$ and Chen $^{[88]}$ studied on information diffusion equilibrium and the change of market pricing efficiency considering receivers' naive bias; Bommel ${ }^{[89]}$ and Garcia and Sangiorgi ${ }^{[90]}$ argued that senders might intentionally release rumors without solid information and built an equilibrium of senders which only spreading rumors; Liu ${ }^{[91]}$ extend the model with the limitations information cost and information time horizon.

As information in the social media are cross linked with multi-sources, study on the multi information source is the extension of single one; meanwhile, fraud information releasing could simulate information manipulation in the social media. Klumpp ${ }^{[92]}$ considered the equilibrium of $M$ information sources as information sender to deliver message to $N$ (larger than $M$ ) receiver, and this model is supported by Becker and Milbourn ${ }^{[93]}$ in studying American credit rating market. This study first introduces information diffusion into Cheap-Talk model and found the similar equilibrium in oligopoly market that is an important innovation and development. Hong, et al. ${ }^{[94]}$ developed a contagion model of rumor diffusion and found out that the diffusion rate and return of assets are strongly related. Besides, Feng, et al. ${ }^{[95]}$ built a rumor diffusion network based on agent-based computational model and found asset pricing and volatility are influenced by individual's network, diffusion rate and information source characteristics.

\subsection{On the Financial Crisis Contagion with Network Approach}

This type of study mainly focused on the controversial problem of risk analysis and prediction on risk contagion, and tried to explain from the perspective of financial network. Profound 
study on financial network and structure may provide better explanations on dynamics of the financial system and further strengthen the whole system and offer effective recommendations to the authority (Schweitzer, et al. ${ }^{[96]}$ ). Lux ${ }^{[97]}$ argued that the network theory is critical to the study on economic system.

Allen and Gale ${ }^{[98]}$ started to research on the financial structure with direct-linking method. They figured out that completeness of inter-bank direct loans is of great importance to the risk contagion. When all the banks connected with loans, the exogenous shocks would diversify and there would be no contagion of risk. However, when this kind of connection is not completed, external shocks would cluster on certain banks, and once they went bankrupt, their early clearance and corresponding damage will contagion to the other banks in the system without direct debt. Watts ${ }^{[99]}$ proposed the definition of global cascade. His research showed that in the stochastic network with correlated nodes, global cascade will be dependent on the overall correlation of the network if the network is spear; on the other hand, is the network is concentrated; the global cascade will depend on the stability of each node. In the first case, global cascade probability follows the power-law distribution and hub nodes are important to global cascade; while in the second situation, global cascade probability follows bimodal distribution and the nodes above average links level can all trigger the global cascade. Besides, the second case is more robust-yet-fragile, which means that the network can survive after multiple times of external shocks before a certain one leading to systemic collapse. At last, he found that heterogeneity of each node has two sides of impacts on the stability of the system: on one hand, the increase of heterogeneity raises the probability of global cascade; on the other hand, when such heterogeneity approaching the peak will reduce the possibility of collapse.

Thurner, et al. ${ }^{[100]}$ emphasized the importance and necessity of contract between banks for the purpose of risk diversification in banking system. Elsinger, et al. ${ }^{[101]}$ focused on mutual credit obligation banking system and offer the single clearing mechanism in which banks repay the outstanding loans based on priority and limited liability. In the meantime, they use comparative static analysis to identify the relationship of the clearing payment vector, the cash flow and nominal liability, which means the clearing payment vector being the concave function of the cash flow and nominal liability. When the nominal liability is given, the clearing payment vector and the cash flow is positively related, the more the cash flow, the larger the vector.

For the random network perspective, Aleksiejuk and Holyst ${ }^{[102]}$ applied two-dimensional directed percolation model to represent the whole financial system to analyze the situation that single bank bankruptcy result in the whole system collapse. They further explained the reason why few banks' bankruptcies lead to the collapse of the whole banking industry in the Great depression period. May and Arinaminpathy ${ }^{[103]}$ studied the influence of the direct link (debt) between financial institutions that lead to the risk contagion with random networks.

\subsection{Banking Systemic Risk Measurement with Network Approach}

Ever since the financial crisis in 2008 , the measurement and control of systemic risk has become a hot research field. The banking system is one of the most crucial elements in the financial system, and both domestic and foreign scholars had carried out exhaustive and profound studies on the measurement and control of banking sectors. However, such studies had conducted even before the financial crisis in 2008. For example, Angelini, Maresca and Russo ${ }^{[104]}$, applied of 
the lending statistics among banks in Italy, building an interbank lending network and studying its impact on the systemic risk. The research found that only $4 \%$ of the banks in Italy are large enough to trigger systemic crisis. The result is significantly smaller than that in American banking system, which attribute to the relatively smaller cash flow in Italian banking system and different network structure. Elsinger, Lehar and Summer ${ }^{[105]}$ used data from Australian banks and the open market data to study the two kinds of risk-spread patterns which may lead to systemic risk: Asset correlation and lending relationship. They found that the measurement that only takes into account the lending relationship significantly underestimates single bank default impact on the entire banking system; however, the asset correlation is the primary risk spread means of systemic risk. They also discovered that the probability of risk contagion by asset correlation is quite limited, but once it happens, most of banks will fail together.

Since the outbreak of the financial crisis in 2008, more scholars studied the systematic risk precaution and management. For example, Huang, Zhou and Zhu ${ }^{[106]}$ proposed analyzing the systematic risks in financial system by drawing on the high frequency data in debt default insurance, and thus increased the accuracy in predicting asset correlations. Further, they added the inter-financial-institutional correlation data to construct a micro-macro model for financial system stress test. Hu, Zhao, Hua and Wong ${ }^{[107]}$, employing the commercial intelligent approach to construct the network-based banking systemic risk management model. By analyzing the real data of interbank financial relationship from The Federal Deposit Insurance Corporation, they studied the risk level of each individual bank in the banking system. They concluded that when huge impact on the market occurs, the inter-bank payment relationship is more capable to influence the survival of each individual bank than the correlation of bank holding portfolio. This conclusion may offer some clues for financial regulators to work out more effective risk-precaution mechanism. After the emergence of Internet data, Cerchiello and Giudici ${ }^{[08]}$ used the finance-related tweets data and financial data to describe the systematic risks of financial market. They described the risks-network in the banking system with tweets data and Gauss model. Basing on that, the researchers made improvement in asset pricing variance and covariance matrix by combing the two data sources and Bayesian posterior approach, which offers a new perspective for systemic risk.

At present, the researches on the systematic risks from the network perspective and their influences on financial institutions raised increasing interests from financial experts. However, there is not profound theoretical interpretation concerning the spread of risks and the measurement of systematic risks. It is, therefore, possible to consider combination of big-data-based analytics and agent-based computation models to develop new principles and approaches for market supervision and systematic risks management.

\section{$5 \quad$ Key Problems of Financial Innovations in Big Data Era}

There are four dimensions of key problems of financial innovations in Big Data era:

\subsection{Product Level}

Big data analysis provides new information sources and client classification criteria for financial institutions, thus allowing them to use these information to design financial products that have never been used before (e.g., catastrophe insurance of insurance company, market 
sentiment based investment fund, etc.), as well as launching differentiated financial products and services according to different types of clients. At the same time, pricing and risk measuring problems towards "data-driven" financial innovative products or services arise.

\section{$5.2 \quad$ Industry Level}

Combining transaction (operational) data with on-line(off-line) non-structured data, applying data mining and analytics, financial service institutions (bank, insurance and security, etc.) will achieve remarkable optimization and innovation on operating cost, service efficiency, business mode and other aspects. So, how will "data-driven" financial innovation change current finance industry operation, allocation of resources and ecosystems?

\subsection{Systemic Level}

On the one hand, although "data-driven" financial innovation brings good solutions for risk measurement and management, it may cause unpredictable impacts on the financial system (e.g., the subprime crisis in 2007); on the other hand, bid data analytical method could become the powerful weapon of financial supervision institutions for systemic risk measurement and management. Meanwhile, the problems of supervision on the "data driven" financial innovation from the perspective of systematic risk and systematic risk management using "Big data" analytic methods arise.

\subsection{Relative Solutions and Significance}

To solve the key problems above, researchers should cooperate with traditional financial institutions or companies, such as banks, insurance companies, trading agencies, Internet finance companies, to combine available non-structured data with account data of these financial institutions to study product pricing principle; its impact on industry innovation modes; and effect to the systematic risk of the financial system based on data driven financial innovation.

Theoretically, traditional financial innovation theory was established on cost reducing, supervision aversion and technological updating, but the "data-driven" financial innovation theory has not yet matured. The research based on the cross fusion of financial innovation theory, risk management theory and relevant research methods of data science will provide a profound understanding of the development and evolution of "data-driven" financial innovation. Besides, the research results will also put forward a new method and perspective for the financial innovation theories of product pricing, industry mode, risk management, etc. Furthermore, it will make a fundamental contribution to the development of the "big data era" financial innovation related theory.

In practice, on the one hand, the research results using public individual data from multiple financial institutions and the Internet will provide a solid theoretical foundation for the optimization and design of product pricing, cost control, operation mode and service innovation of the financial institutions. On the other hand, the outcome from study of big data method applications in industry supervision and systematic risk measurement will provide methodological support and policy recommendations for regulatory authorities to manage the industry's internal risk and financial systematic risk. 


\section{Future Research Frontiers and Development Trend}

Among research on big data based financial innovation and risk management study, some area have already made series of significant theoretical breakthrough, such as on the innovation of P2P internet lending platform; securities market participant's behavior evolution in social medias; systemic risk from network perspective and the effect exerted on financial institutions. However, as it is easier to obtain more various and cross-correlated micro-financial data in the big data time, the information cost is greatly reduced, which brings a new opportunity for finance industry. Based comprehensive consideration on the important achievements and practical requirements that already obtained, we conclude the research frontier and development trend in this field as following:

1) Using big data to extend the researches on securities market individual participant's behavior and evolution to the entire financial system participant's behavior and evolution. Even though the existing research had already applied big data to microscopic behavior study in financial market, but with the continuous development of big data, it is possible to reflect market participant's behavior more precisely with comprehensive cross-correlated data. Especially, from the perspective of behavior evolution of big data background to integrate the cross-correlated data among banks, insurance companies, P2P platforms, and exchange insinuations to carry on microscopic analysis will be an important research direction in the future.

2) By extending the existing financial innovation model, financial service institutions can integrate their own transaction data and possible external data to carry on product pricing and service innovation research. In the future research with the development of information technology, it is possible to study on the cost reduction in financial service institution; the promotion of the risk measure method; understanding customers' incomplete aspects, and regulations. Specifically, research on the innovation of resources integration of financial institutions internally, in the meantime, the new business model and service innovation among different financial institutions would also be considered.

3) Developing market regulation and systematic risk management method based on big data and agent-based computational models. Due to lack of account data, scholars can only focus on the false information on Internet and asset pricing without considering the cash flows and investor trading behavior. Thus, only relying on the changes of characteristics in Internet information diffusion is not enough to estimate whether information manipulation exists or not effectively. From regulation perspective, as long as the transaction data is available, the influence of misleading information to asset pricing in the security market requires further studying.

Acknowledgements The authors gratefully acknowledge the editor and two anonymous referees for their insightful comments and helpful suggestions that led to a marked improvement of the article.

\section{References}

[1] Edelman B. Using Internet data for economic research. Journal of Economic Perspectives, 2012, 26(2): 189-206.

[2] Varian H R. Big Data: New tricks for econometrics. Journal of Economic Perspectives, 2014, 28(2): 3-28. 
[3] Paravisini D, Rappoport V, Ravina E. Risk aversion and wealth: Evidence from person-to-person lending portfolios. National Bureau of Economic Research Working Paper, 2013.

[4] Zhang Z. Credit risk preference in e-finance: An empirical analysis of P2P lending. Pacific Asia Conference on Information Systems Working Paper, 2014.

[5] Li S, Qiu J, Lin Z, et al. Do borrowers make homogeneous decisions in online P2P lending market? An empirical study of PPDai in China. In Service Systems and Service Management (ICSSSM), 2011 8th International Conference on (pp. 1-6). IEEE.

[6] Krumme K A, Herrero S. Lending behavior and community structure in an online peer-to-peer economic network. In Computational Science and Engineering, 2009. CSE'09. IEEE on International Conference, 2009, 4: 613-618.

[7] Yum H, Lee B, Chae M. From the wisdom of crowds to my own judgment in microfinance through online peer-to-peer lending platforms. Electronic Commerce Research and Applications, 2012, 11(5): 469-483.

[8] Ceyhan S, Shi X, Leskovec J. Dynamics of bidding in a P2P lending service: Effects of herding and predicting loan success. In Proceedings of the 20th international conference on World Wide Web, ACM, 2011, 547-556.

[9] Li S, Lin Z X, Qiu J X, et al. How friendship networks work in online P2P lending markets. Nankai Business Review International, 2015, 6(1): 42-67.

[10] Herzenstein M, Dholakia U M, Andrews R L. Strategic herding behavior in peer-to-peer loan auctions. Journal of Interactive Marketing, 2011, 25(1): 27-36.

[11] Lee E, Lee B. Herding behavior in online P2P lending: An empirical investigation. Electronic Commerce Research and Applications, 2012, 11(5): 495-503.

[12] Luo B, Lin Z. A decision tree model for herd behavior and empirical evidence from the online P2P lending market. Information Systems and e-Business Management, 2013, 11(1): 141-160.

[13] Li Y, Guo Y, Zhang W. The analysis of impact factors on loan performance in Chinese P2P microfinance market. Journal of Financial Research, 2013(7): 126-138.

[14] Chen N, Ghosh A, Lambert N S. Auctions for social lending: A theoretical analysis. Games and Economic Behavior, 2014, 86: 369-391.

[15] Redmond U, Cunningham P. A temporal network analysis reveals the unprofitability of arbitrage in the prosper marketplace. Expert Systems with Applications, 2013, 40(9): 3715-3721.

[16] Burtch G, Ghose A, Wattal S. An empirical examination of the antecedents and consequences of contribution patterns in crowd-funded markets. Information Systems Research, 2013, 24(3): 499-519.

[17] Lin M, Prabhala N R, Viswanathan S. Judging borrowers by the company they keep: Friendship networks and information asymmetry in online peer-to-peer lending. Management Science, 2013, 59(1): 17-35.

[18] Emekter R, Tu Y, Jirasakuldech B, et al. Evaluating credit risk and loan performance in online Peer-toPeer (P2P) lending. Applied Economics, 2015, 47(1): 54-70.

[19] Michels J. Do unverifiable disclosures matter? Evidence from peer-to-peer lending. Accounting Review, 2012, 87(4): 1385-1413.

[20] Barasinska N, Schafer D. Is crowd funding different? Evidence on the relation between gender and funding success from a German Peer-to-Peer lending platform. German Economic Review, 2014, 15(4): 436-452.

[21] Ravina E. The effect of beauty and personal characteristics in credit markets. SSRN Working Paper (1107307), 2008.

[22] Larrimore L, Jiang L, Larrimore J, et al. Peer to peer lending: The relationship between language features, trustworthiness, and persuasion success. Journal of Applied Communication Research, 2011, 39(19): 1937 .

[23] Herzenstein M, Sonenshein S, Dholakia U M. Tell me a good story and I may lend you money: The role of narratives in peer-to-peer lending decisions. Journal of Marketing Research, 2011, 48(SPL): S138-S149.

[24] Ashta A, Assadi D. Does social lending incorporate social technologies? The use of web 2.0 technologies in online P2P lending. CEB Working Papers, 2009.

[25] Herzenstein M, Andrews R L, Dholakia U, et al. The democratization of personal consumer loans? Determinants of success in online peer-to-peer lending communities. Boston University School of Management Research Paper, 2008.

[26] Qiu J, Laine J, Lin Z, et al. Pricing strategies in electronic two-sided markets — Evidence from the online P2P lending marketplace. SIGBPS Workshop on Business Processes and Services (BPS'12), 2012. 
[27] Berger S C, Gleisner F. Emergence of financial intermediaries in electronic markets: The case of online P2P lending. BuR-Business Research, 2009, 2(1): 39-65.

[28] Iyer R, Ijaz A, Erzo K, et al. Inferring asset quality: Determining borrower creditworthiness in peer-to-peer lending markets. 2010.

[29] Iyer R, Khwaja A, Luttmer E, et al. Screening in new credit markets: Can individual lenders infer borrower creditworthiness in peer-to-peer lending? In AFA 2011 Denver Meetings Paper, 2009.

[30] Wang Y, Lin Z. The importance of objective and dynamic credit evaluation in P2P lending market. Working Paper, 2014.

[31] Freedman S, Jin G Z. Do social networks solve information problems for peer-to-peer lending? Evidence from Prosper.com. Working Paper, 2008.

[32] Lin M. Peer-to-peer lending: An empirical study. AMCIS 2009 Doctoral Consortium, 2009: 17.

[33] Weiss G N, Pelger K, Horsch A. Mitigating adverse selection in P2P lending: Empirical evidence from Prosper.com. Available at SSRN 1650774, 2010.

[34] Puro L, Teich J E, Wallenius H, et al. Borrower decision aid for people-to-people lending. Decision Support Systems, 2010, 49(1): 52-60.

[35] Zhao H, Wu L, Liu Q, et al. Investment recommendation in P2P lending: A portfolio perspective with risk management. Working Paper, 2014.

[36] Luo C, Xiong H, Zhou W, et al. Enhancing investment decisions in P2P lending: an investor composition perspective. In Proceedings of the 17th ACM SIGKDD International Conference on Knowledge Discovery and Data Mining, ACM, 2011, 292-300.

[37] Riggins F J, Weber D M. A model of peer-to-peer (P2P) social lending in the presence of identification bias. In Proceedings of the 13th International Conference on Electronic Commerce, ACM, 2011, 23.

[38] Batsell J. Gossip central - Internet message boards can leave some stocks hanging by a thread. Seattle Times, 1998.

[39] Bennett J. Traffic on financial web pages rises when the market falls. Dow Jones News Service, 1998.

[40] Goldstein A. Money messages: Electronic message boards are a good way to get investing facts and fiction. Dallas Morning News, 1998.

[41] Harmon A. The market turmoil: Investors on line. New York Times, 1998.

[42] Maremount M. Predeal trading in U.S. surgical puts spotlight on cyberinvestors. Wall Street Journal, May $28,1998$.

[43] Medill G. Chicago firm wants to know what Yahoo! left messages. Chicago Daily Herald, 1998.

[44] Wysocki P. Cheap talk on the web: The determinants of postings on stock message boards. University of Michigan Business School Working Paper (98025), 1998.

[45] Tumarkin R, Whitelaw R F. News or noise? Internet postings and stock prices. Financial Analysts Journal, 2001, 57(3): 41-51.

[46] Bowen R M, Davis A K, Rajgopal S. Determinants of revenue recognition practices for Internet firms. Contemporary Accounting Research, 2002, 19(4): 523-562.

[47] Clarkson, Joyce P D, Tutticci I. Market reaction to takeover rumour in internet discussion sites. Accounting and Finance, 2006, 46(1): 31-52.

[48] Dewally M. Internet investment advice: Investing with a rock of salt. Financial Analysts Journal, 2003, 59(4): $65-77$.

[49] Bohme R, Holz T. The effect of stock spam on financial markets. SSRN Working Paper, 2006.

[50] Hanke M, Hauser F. On the effects of stock spam e-mails. Journal of Financial Markets, 2008, 11(1): $57-83$.

[51] Hu N, Liu L, Tripathy A, et al. Value relevance of blog visibility. Journal of Business Research, 2011, 64(12): 1361-1368.

[52] Saxton G. Financial blogs and information asymmetry between firm insiders and outsiders. Proceedings of American Accounting Association, Anaheim, CA, USA, 2008.

[53] Mondria J, Wu T, Zhang Y. The determinants of international investment and attention allocation: Using internet search query data. Journal of International Economics, 2010, 82(1): 85-95.

[54] Zhang Y, Zhang W, Jin X, et al. Does the Internet know more? Open source information and asset pricing. Systems Engineering — Theory \& Practice, 2011, 31(4): 577-586.

[55] Antweiler W, Frank M Z. Is all that talk just noise? The information content of internet stock message 
boards. Journal of Finance, 2004, 59(3): 1259-1294.

[56] Das S R, Chen M Y. Yahoo! for Amazon: Sentiment extraction from small talk on the web. Management Science, 2007, 53(9): 1375-1388.

[57] Zhang Y, Swanson P E, Prombutr W. Measuring effects on stock returns of sentiment indexes created from stock message boards. Journal of Financial Research, 2012, 35(1): 79-114.

[58] Bollen J, Mao H, Zeng X. Twitter mood predicts the stock market. Journal of Computational Science, 2011, 2(1): 1-8.

[59] Felton J, Kim J. Warnings from the Enron message board. Journal of Investing, 2002, 11(3): $29-52$.

[60] Gu B, Konana P, Rajagopalan B, et al. Competition among virtual communities and user valuation: The case of investing-related communities. Information Systems Research, 2007, 18(1): 68-85.

[61] De Choudhury M, Sundaram H, John A, et al. Can blog communication dynamics be correlated with stock market activity? In Proceedings of the 19 ACM Conference on Hypertext and Hypermedia, Pittsburgh, PA, USA: ACM, 2008.

[62] Da Z, Engelberg J, Gao P. In search of attention. The Journal of Finance, 2011, 66(5): 1461-1499.

[63] Merton R C. A simple model of capital market equilibrium with incomplete information. The Journal of Finance, 1987, 42(3): 483-510.

[64] Sims C A. Implications of rational inattention. Journal of monetary Economics, 2003, 50(3): 665-690.

[65] Hirshleifer D, Teoh S H. Limited attention, information disclosure, and financial reporting. Journal of Accounting and Economics, 2003, 36(1): 337-386.

[66] Grullon G, Kanatas G, Weston J P. Advertising, breadth of ownership, and liquidity. Review of Financial Studies, 2004, 17(2): 439-461.

[67] Chemmanur T, Yan A. Product market advertising and new equity issues. Journal of Financial Economics, 2009, 92(1): 40-65.

[68] Chan W S. Stock price reaction to news and no-news: Drift and reversal after headlines. Journal of Financial Economics, 2003, 70(2): 223-260.

[69] Fang L, Peress J. Media coverage and the cross-section of stock returns. The Journal of Finance, 2009, 64(5): 2023-2052.

[70] Barber B M, Odean T. All that glitters: The effect of attention and news on the buying behavior of individual and institutional investors. Review of Financial Studies, 2008, 21(2): 785-818.

[71] Seasholes M S, Wu G. Predictable behavior, profits, and attention. Journal of Empirical Finance, 2007, 14(5): 590-610.

[72] Bank M, Larch M, Peter G. Google search volume and its influence on liquidity and returns of German stocks. Financial markets and portfolio management, 2011, 25(3): 239-264.

[73] Vlastakis N, Markellos R N. Information demand and stock market volatility. Journal of Banking and Finance, 2012, 36(6): 1808-1821.

[74] Drake M S, Roulstone D T, Thornock J R. Investor information demand: Evidence from Google searches around earnings announcements. Journal of Accounting Research, 2012, 50(4): 1001-1040.

[75] Dzielinski M. Measuring economic uncertainty and its impact on the stock market. Finance Research Letters, 2012, 9(3): 167-175.

[76] Yu Q, Zhang B. Limited attention and stock performance: An empirical study using Baidu index as the proxy for investor attention. Journal of Financial Research, 2012, 385: 152-165.

[77] Zhang W, Shen D, Zhang Y, et al. Open source information, investor attention, and asset pricing. Economic Modelling, 2013, 33(0): 613-619.

[78] Liu F, Ye Q, Li Y J. Impacts of interactions between news attention and investor attention on stock returns: Empirical investigation on financial shares in China. Journal of Management Sciences in China, 2014, 17(1): 72-85.

[79] Zhang Y, Feng L, Jin X, et al. Internet information arrival and volatility of SME PRICE INDEX. Physica A: Statistical Mechanics and Its Applications, 2014, 399: 70-74.

[80] Lamoureux C G, Lastrapes W D. Heteroskedasticity in stock return data: Volume versus GARCH effects. The Journal of Finance, 1990, 45(1): 221-229.

[81] Kalev P S, Liu W M, Pham P K, et al. Public information arrival and volatility of intraday stock returns. Journal of Banking and Finance, 2004, 28(6): 1441-1467.

[82] Wagner N, Marsh T A. Surprise volume and heteroskedasticity in equity market returns. Quantitative 
Finance, 2005, 5(2): 153-168.

[83] Fleming J, Kirby C, Ostdiek B. Stochastic volatility, trading volume, and the daily flow of information. The Journal of Business, 2006, 79(3): 1551-1590.

[84] McMillan D G, Garcia R Q. Does information help intra-day volatility forecasts?. Journal of Forecasting, 2013, 32(1): 1-9.

[85] Crawford V P, Sobel J. Strategic information transmission. Econometrica: Journal of the Econometric Society, 1982, 50(6): 1431-1451.

[86] Benabou R, Laroque G. Using privileged information to manipulate markets: Insiders, gurus, and credibility. The Quarterly Journal of Economics, 1992, 59(3): 921-958.

[87] Crawford V P. Lying for strategic advantage: Rational and boundedly rational misrepresentation of intentions. American Economic Review, 2003, 93(1): 133-149.

[88] Chen Y. Perturbed communication games with honest senders and naive receivers. Journal of Economic Theory, 2011, 146(2): 401-424.

[89] Bommel J V. Rumors. The Journal of Finance, 2003, 58(4): 1499-1520.

[90] Garcia D, Sangiorgi F. Information sales and strategic trading. Review of Financial Studies, 2011, 24(9): 3069-3104.

[91] Liu Q. Information acquisition and reputation dynamics. The Review of Economic Studies, 2011, 78(4): 1400-1425.

[92] Klumpp T. Communication in financial markets with several informed traders. Economic Theory, 2007, 33(3): 437-456.

[93] Becker B, Milbourn T. How did increased competition affect credit ratings?. Journal of Financial Economics, 2011, 101(3): 493-514.

[94] Hong D, Hong H G, Ungureanu A. An epidemiological approach to opinion and price-volume dynamics. AFA 2012 Chicago Meetings Paper, 2011.

[95] Feng X, Zhang W, Zhang Y, et al. Information identification in different networks with heterogeneous information sources. Journal of Systems Science and Complexity, 2014, 27(1): 92-116.

[96] Schweitzer F, Fagiolo G, Sornette D, et al. Economic networks: The new challenges. Science, 2009, 325(5939): 422-425.

[97] Lux T. Network theory is sorely required. Nature, 2011, 469(7330): 303-303.

[98] Allen F, Gale D. Financial contagion. Journal of Political Economy, 2000, 108(1): 1-33.

[99] Watts D J. A simple model of global cascades on random networks. Proceedings of the National Academy of Sciences, 2002, 99(9): 5766-5771.

[100] Thurner S, Hanel R, Pichler S. Risk trading, network topology and banking regulation. Quantitative Finance, 2003, 3(4): 306-319.

[101] Elsinger H, Lehar A, Summer M. Using market information for banking system risk assessment. Available at SSRN 787929, 2005.

[102] Aleksiejuk A, Holyst J A. A simple model of bank bankruptcies. Physica A: Statistical Mechanics and Its Applications, 2001, 299(1-2): 198-204.

[103] May R M, Arinaminpathy N. Systemic risk: The dynamics of model banking systems. Journal of the Royal Society Interface, 2010, 7(46): 823-838.

[104] Angelini P, Maresca G, Russo D. Systemic risk in the netting system. Journal of Banking and Finance, 1996, 20(5): 853-868.

[105] Elsinger H, Lehar A, Summer M. Risk assessment for banking systems. Management Science, 2006, 52(9): $1301-1314$.

[106] Huang X, Zhou H, Zhu H. A framework for assessing the systemic risk of major financial institutions. Journal of Banking and Finance, 2009, 33(11): 2036-2049.

[107] Hu D, Zhao J L, Hua Z, et al. Network-based modeling and analysis of systemic risk in banking systems. MIS Quarterly, 2012, 36(4): 1269-1291.

[108] Cerchiello P, Giudici P. How to measure the quality of financial tweets. Quality and Quantity, 2015, 1-19. 